\section{(1) \\ CrossMark}

\title{
Early diagnosis of COPD: myth or a true perspective
}

\author{
Maria Eugenia Laucho-Contreras ${ }^{1,2}$ and Mark Cohen-Todd ${ }^{3}$ \\ Affiliations: ${ }^{1}$ Fundación Neumológica Colombiana, Bogota, Colombia. ${ }^{2}$ GlaxoSmithKline, Bogota, Colombia. \\ ${ }^{3}$ Hospital Centro Medico, Guatemala City, Guatemala.
}

Correspondence: Maria Eugenia Laucho-Contreras, Fundación Neumológica Colombiana, Kra. 13b \#161-85, Bogota 110111, Colombia. E-mail: mlauchodgmail.com

@ERSpublications

Is it possible to answer the question of whether early diagnosis of COPD is a myth or reality? If we define the objectives clearly, early detection will play a key role in having a positive impact on the prognosis of patients with COPD. https://bit.ly/32crfPL

Cite this article as: Laucho-Contreras ME, Cohen-Todd M. Early diagnosis of COPD: myth or a true perspective. Eur Respir Rev 2020; 29: 200131 [https://doi.org/10.1183/16000617.0131-2020].

ABSTRACT The early stages of COPD have recently become a hot topic as many new risk factors have been proposed, but substantial knowledge gaps remain in explaining the natural history of the disease. If we are to modify the outcomes of COPD, early detection needs to play a critical role. However, we need to sort out the barriers to early detection and have a better understanding of the definition of COPD and its diagnosis and therapeutic strategies to identify and treat patients with COPD before structural changes progress. In this review, we aim to clarify the differences between early COPD, mild COPD and early detection of COPD, with an emphasis on the clinical burden and how different outcomes (quality of life, exacerbation, cost and mortality) are modified depending on which definition is used. We will summarise the evidence for the new multidimensional diagnostic approaches to detecting early pathophysiologic changes that potentially allow for future studies on COPD management strategies to halt or prevent disease development.

\section{Introduction}

In the past few decades, research into COPD has increased substantially, but significant gaps remain regarding diagnosis and, in particular, early detection. COPD is underdiagnosed or misdiagnosed in approximately two-thirds of patients at risk of COPD in many population- and primary care-based studies $[1,2]$. To decrease the impact of COPD, preventive and therapeutic strategies that mitigate clinical progression, and ultimately reduce the burden on healthcare systems, should be provided and the identification of patients with early-stage COPD would improve outcomes. However, we must acknowledge some significant barriers: 1) the COPD definition is operational rather than pathophysiological and disregards disease heterogeneity; 2) the definitions for early COPD versus early diagnosis are not standardised; and 3) there are very few validation studies of treatment strategies linked to early detection, early COPD, symptomatic smokers (at risk of developing COPD) or mild COPD.

\section{Definitions for early diagnosis of COPD Early COPD}

A recently proposed definition to diagnose early COPD takes several factors into account. Early COPD is diagnosed in patients aged $<50$ years with $\geqslant 10$ pack-years smoking history and one or more of the following: 1) post-bronchodilator forced expiratory volume in $1 \mathrm{~s} /$ forced vital capacity ( $\mathrm{FEV}_{1} / \mathrm{FVC}$ ) less

Provenance: Commissioned article, peer reviewed

Received: 2 May 2020 | Accepted after revision: 7 July 2020

Copyright CERS 2020. This article is open access and distributed under the terms of the Creative Commons Attribution Non-Commercial Licence 4.0. 
than the lower limit of normal (LLN); 2) compatible computed tomography (CT) abnormalities (visual emphysema, air trapping or bronchial thickening graded mild or worse); and 3) evidence of accelerated $\mathrm{FEV}_{1}$ decline $\left(\geqslant 60 \mathrm{~mL} \cdot \mathrm{year}^{-1}\right)$ that is accelerated relative to FVC [3]. This definition excludes patient-reported respiratory symptoms, given their discordance with structural lung changes. Currently, several cohorts are validating these criteria and these may need to be refined to capture early phase developments [3].

\section{Mild COPD}

Mild COPD is defined by Latin American COPD guidelines (EPOC-ALAT) as patients with 0-1 modified Medical Research Council (mMRC) dyspnoea, $\mathrm{FEV}_{1}>80 \%$ and no exacerbations [4]. According to the Global Initiative for Chronic Obstructive Lung Disease (GOLD), mild COPD is equivalent to GOLD A (0$1 \mathrm{mMRC}$ dyspnoea and no exacerbations) [5]. However, there is evidence that the prevalence of mild COPD varies according to the classification used (GOLD or ALAT) [6].

COPD progression is heterogeneous, but longitudinal cohorts reveal that only $20-40 \%$ of patients progress to a worse COPD stage [7, 8]; after 2 years of follow-up, two-thirds of patients with COPD maintain the same GOLD classification [9]. However, one-third of patients with mild disease have faster decline in $\mathrm{FEV}_{1}$ compared with the population without COPD $[10,11]$. At present, we do not have exact biomarkers that allow us to correctly differentiate patients with a COPD phenotype with worse progression from patients with COPD phenotypes and more benign courses. Therefore, early COPD is different to mild COPD, mainly because the latter concept does not address the underlying pathological changes, and does not adequately discriminate patients with COPD at the beginnings of the disease from patients at the later stages $[7,8,12]$.

\section{Early diagnosis of COPD}

Early diagnosis of COPD has many interpretations. A recent survey showed that most pulmonologists consider "early" diagnosis as COPD diagnosed before the beginning of symptoms [13]. In a real-life retrospective study, $85 \%$ of patients with COPD had consulted for respiratory symptoms at least once in the 5 years prior to diagnosis [14]. In this study, the authors classified patients with COPD as having an early diagnosis if patients had $\leqslant 2$ registered indicators during the past 5 years before COPD diagnosis (indicators were pneumonia, respiratory diseases other than pneumonia, prescription of oral steroids, prescription of antibiotics for airway and lung infections, prescriptions for respiratory disease targeted to relieve respiratory symptoms and lung function measurements). Patients with $\geqslant 3$ indicators (registered $>90$ days before diagnosis) were classified as having a late diagnosis [15]. This classification demonstrates that early diagnosis patients have a better prognosis than late diagnosis patients.

\section{At-risk population for COPD}

Another important group is the population at risk of developing COPD; described as GOLD 0 and defined as individuals exposed to risk factors for COPD, with normal spirometry and chronic symptoms (cough, sputum and/or dyspnoea) [16]. There is evidence that this group has worse outcomes than nonsymptomatic smokers [10, 17]. Of this group, 30-40\% will develop lung obstruction [10], 57\% have some structural damage (emphysema, small airway thickening and gas air trapping) and, after 5-years of follow-up, have increased lung function decline (OR 1.31, 95\% CI 1.04-1.65) [18]. Furthermore, during a 15-year follow-up in GOLD 0 patients, smoking cessation predicted the subsequent absence of chronic symptoms (OR 5.7, 95\% CI 3.5-9.2) [19]. Therefore, the risk-benefit of identifying this group in the population must be individualised, and therapeutic strategies should include nonpharmacological measures and follow-up [5].

\section{Summary of the differences between early COPD, mild COPD and the at-risk population}

The differences between these definitions are that: early COPD emphasises age, capturing early phase disorders in high-risk individuals before the $\mathrm{FEV}_{1} / \mathrm{FVC}$ ratio falls $<0.7$; mild COPD focuses on the severity of the disease, although the patients could have mild COPD for years; early detection of COPD primarily focuses on defining a relatively short time-frame from the beginning of symptoms to diagnosis; and the at-risk population (GOLD 0) aims to identify patients (symptomatic smokers) who may go on to develop COPD (table 1).

Recently, numerous studies have shown that the presence of asthma [21], exposure to tobacco smoke [22$25]$ and repeated respiratory infections $[22,23]$ during childhood increases the risk of COPD in adulthood. Moreover, in the Childhood Asthma Management Project (CAMP), 11\% of subjects with reduced lung growth patterns had COPD compatible lung function at the mean \pm SD age of $26 \pm 1.8$ years [26]. However, although abnormal lung development is a risk factor for COPD [5], it is not included in definitions related 
TABLE 1 Criteria for early detection of COPD

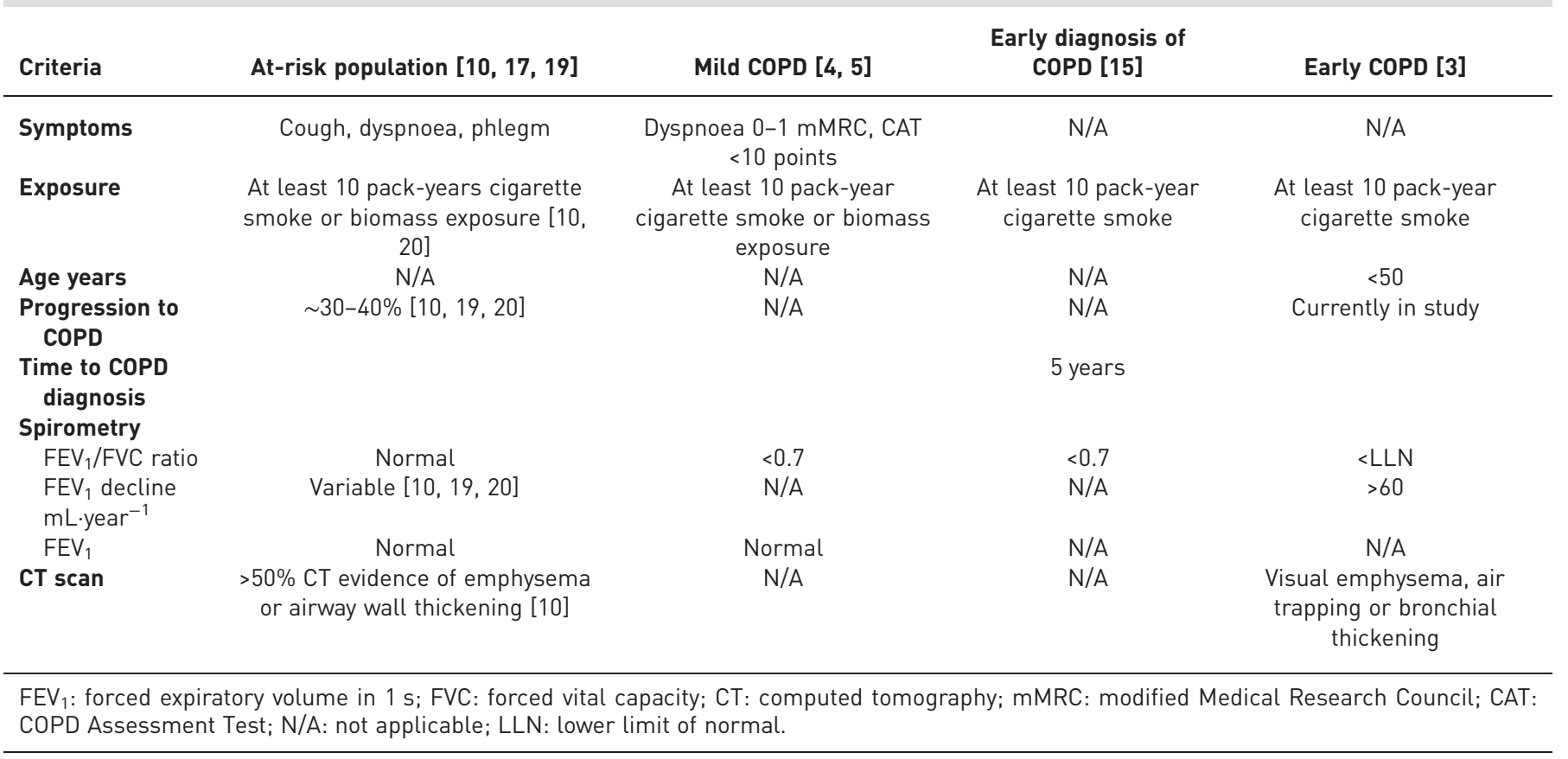

to early COPD probably because these definitions focus on functional parameters (age, lung function and pulmonary structural changes) rather than underlying pathophysiological mechanisms $[3,6,15,16]$.

\section{Clinical burden and outcomes of early diagnosis of COPD}

Issues that need consideration for early diagnosis COPD are the possibilities of misdiagnosis or over-diagnosis due to the lack of markers to detect early-onset airway pathology [27]. COPD underdiagnosis is common (60-86\%), representing a missed opportunity to decrease the burden of disease through optimal preventive and therapeutic management. However, over-diagnosis is also frequent (4$64 \%)[1,2]$, leading to unnecessary COPD treatments with their risks and costs, poor health-related quality of life (HRQoL) and missed detection and treatment for other diseases. However, COPD is a significant public health problem, even in the early stages, and several studies have shown that undiagnosed patients with COPD have worse health outcomes (HRQoL, exacerbations and risk of pneumonia) than the general population $[28,29]$ and have similar levels of use of health resources as patients diagnosed with COPD [30].

In a recent study that only used one of the three criteria of the proposed definition for early COPD diagnosis [3] $\left(\mathrm{FEV}_{1} / \mathrm{FVC}<\mathrm{LLN}\right)$, the prevalence of COPD was $7 \%, 10 \%$ and $15 \%$ for those aged $20-29$, 30-39 and 40-49 years, respectively[31]. Therefore, this number is likely to be an underestimate and probably would increase if the two other definition criteria had been used (CT abnormalities, FEV decline $>60 \mathrm{~mL} \cdot \mathrm{year}^{-1}$ ). The average age of that group (early COPD) was 45.9 years; this group overall had more pack-years, a higher proportion of current smokers, more chronic respiratory symptoms, lower lung function, an increased risk of acute obstructive lung disease hospitalisations (OR 6.42, 95\% CI 3.39-12.2), acute pneumonia hospitalisations (OR 2.03, 95\% CI 1.43-2.88), costs and all-cause mortality (OR 1.79, 95\% CI 1.28-2.52) than the population of smokers (>10 pack-years) without COPD [31].

Also, if we evaluate the data on at-risk patients, several studies showed that smokers with respiratory symptoms have higher mortality, faster lung function decline, and more exacerbations than smokers without symptoms [20,31].

Using all the criteria for early diagnosis of COPD in a retrospective cohort, the group of patients with an early diagnosis of COPD had fewer exacerbations (OR 1.89, 95\% CI 1.83-1.96; p<0.0001), fewer comorbidities and lower healthcare utilisation in the 2 years following diagnosis compared with the late diagnosis group [15].

These findings demonstrate the benefit of detecting patients with COPD in the early stages despite preserved or mildly obstructed spirometry, with particular impacts on outcomes in those with chronic respiratory symptoms and COPD risk factors $[13,15,18,31]$. 


\section{Diagnostic approach for early detection of COPD}

Screening spirometry (case finding) is only recommended for those patients with COPD risk factors and symptoms, and is not recommended for asymptomatic people with COPD risk factors [5, 32]. However, many individuals at increased risk for COPD self-restrict activities to minimise symptoms, do not report dyspnoea during visits or are poor perceivers of their symptoms [33, 34]. Therefore, "asymptomatic" patients should be directly questioned about symptoms, physical activity, possible minor unreported exacerbations and previous personal and family lung disorders to activate diagnostic study protocols.

Opportunistic case finding approaches in primary care are a feasible option for early detection of COPD. Externally validated pre-screening questionnaires have been developed to select high-risk patients for further spirometry screening to confirm the diagnosis of COPD (table 2) [35-39]. These questionnaires have not been studied in asymptomatic high-risk patients and warrant further testing in this subgroup.

Spirometry with a post-bronchodilator $\mathrm{FEV}_{1} / \mathrm{FVC}<0.70$ and/or LLN criteria is the gold standard to confirm COPD diagnosis. However, respiratory symptoms and structural changes in the lung are frequently discordant with spirometric results. Furthermore, $\mathrm{FEV}_{1}$ and $\mathrm{FVC}$ have diurnal variations, depending on age, sex, smoking, region and severity of COPD, which affects confirmation in the early stages [40].

Novel approaches, including business process management strategy support systems, avoid the weaknesses in the current COPD diagnostic systems [41]. The use of earlier indicators has been proposed.

\section{Spirometry}

The alternative spirometric ratios used to investigate earlier changes not detected by $\mathrm{FEV}_{1} / \mathrm{FVC}_{\text {or }} \mathrm{FEV}_{1}$ and that detect small airway abnormalities, air trapping and hyperinflation are described below [42].

Lung capacity ratios

FVC may underestimate slow vital capacity (SVC) in the presence of small airway obstruction [43]. Using the 2.5th percentile as LLN, the $\mathrm{FEV}_{1} / \mathrm{SVC}$ ratio increases accuracy in detecting early mild obstruction in patients aged $<60$ years, $\mathrm{FEV}_{1}>70 \%$ pred and body mass index $>30 \mathrm{~kg} \cdot \mathrm{m}^{-2}$, when compared with $\mathrm{FEV}_{1} /$ FVC ratio (discordance of 20.4\%) [44,45]. The lack of reference values for $\mathrm{FEV}_{1} / \mathrm{SVC}$ ratio limits its widespread use for early stage COPD diagnosis [45].

\section{Time-fractioned lung/volume ratio}

$\mathrm{FEV}_{6}$ is more reproducible and less difficult to perform than FVC [46] and can be performed with office-based, hand-held devices. $\mathrm{FEV}_{1} / \mathrm{FEV}_{6}$ ratio $<74 \%$ pred has been shown to be an independent predictor of mortality, hospitalisations and future lung function decline $[47,48]$. The $\mathrm{FEV}_{1} / \mathrm{FEV}_{6}$ ratio is less sensitive than $\mathrm{FEV}_{1} / \mathrm{FVC}$ in detecting an obstruction, although a reduced $\mathrm{FEV}_{1} / \mathrm{FEV}_{6}$ ratio is correlated with more significant abnormalities in diffusing capacity, airway wall thickness and air trapping facilitating the early diagnosis of COPD $[49,50]$.

\section{Flow-based measurement}

This is a more direct measure of small airway function than time-based indices and correlates with air trapping seen on chest CT imaging [51]. For COPD, forced expiratory flow at $25-75 \% \mathrm{FVC}\left(\mathrm{FEF}_{25-75 \%}\right)$ is

TABLE 2 Predictive accuracy of questionnaires externally validated and measured against post-bronchodilator forced expiratory volume in $1 \mathrm{~s} /$ forced vital capacity $\left(\mathrm{FEV}_{1} / \mathrm{FVC}\right)<0.70$

\begin{tabular}{lcccc} 
Questionnaire & Score & Sensitivity \% & Specificity & ROC AUC \\
\hline COPD Diagnostic Questionnaire (CDQ) [35] & $>16.5$ & $80-91$ & $24-49$ & $0.65-0.73$ \\
Lung Function Questionnaire (LFQ) [36] & $\leqslant 18$ & 88 & 0.65 & $0.57-0.70$ \\
COPD Population Screener (COPD-PS) [37] & $\geqslant 5$ & 79 & 35 & $0.70-0.73 / 0.67-0.70$ \\
PUMA Score (Primary Care/PLATINO) [38] & $\geqslant 5$ & $81.8-88.6 / 46.7-56.2$ & $33.5-41.8 / 79.8-83.3$ & 93.1 \\
CAPTURE+PEF [39] & $>2$ & & & 0.93 \\
$\quad$ PEF L.min & & & & \\
$\quad$ Male & $\leqslant 350$ & & &
\end{tabular}

ROC AUC: receiver operating characteristic area under the curve; PUMA: Prevalence Study and Regular Practice, Diagnosis and Treatment, Among General Practitioners in Populations at Risk of COPD in Latin America; PLATINO: Proyecto LatinoAmericano de Investigación en Obstrucción Pulmonar (COPD research project in Latin America); CAPTURE: COPD Assessment in Primary Care To Identify Undiagnosed Respiratory Disease and Exacerbation Risk; PEF: peak expiratory flow. 
lower in current, former and second-hand smokers with no evidence of airflow obstruction compared with healthy individuals $[52,53]$. Nonetheless, the clinical utility of $\mathrm{FEF}_{25-75 \%}$ has been limited, primarily by the wide range of normal values and within-subject variability making standardisation of this metric challenging.

\section{Plethysmography with diffusing capacity of the lung for carbon monoxide}

Inspiratory capacity (IC), total lung capacity (TLC), IC/TLC and residual volumes are used to detect air trapping, hyperinflation and response to bronchodilators. These measurements offer evidence of small airway involvement and can detect "susceptible" smokers. A retrospective study revealed abnormal lung volumes and air trapping to be present in $>30 \%$ of smokers with preserved spirometry [54].

Adding the diffusion capacity measurement can detect earlier abnormalities in small airway disease before spirometric and TLC changes occur [55]. In a cohort of smokers, in the group with normal spirometry/ normal diffusing capacity of the lung for carbon monoxide $\left(D_{\mathrm{LCO}}\right)$, only $3 \%$ developed COPD compared with $22 \%$ in the group with normal spirometry/low $D_{\text {LCO }}(<80 \%$ pred $)$ over $45 \pm 20$ months of follow-up [55].

\section{Chest tomography}

Advanced analytic methods applied to CT images can quantify airway and parenchymal abnormalities prior to changes in lung function [56-58]. The COPDGene study [18] demonstrated progression at 5 years of the CT airway-predominant pattern from GOLD 0 to preserved ratio-impaired spirometry (PRISm) (33\%) and from PRISm to GOLD 2-4 (37.8\%), while the progression of the emphysema-predominant pattern is primarily from GOLD 0 to GOLD 1 (11.8\%) and from GOLD 1 to GOLD 2-4 (25\%). Of the participants in the PRISm group, who were heavy current and former smokers, $35.8 \%$ progressed to GOLD 2-4 but none moved into GOLD 0 or GOLD 1. Therefore, PRISm physiology represents an advanced and progressive disease state, which is associated with airway-predominant disease and carries a poor prognosis despite smoking cessation [18].

In SPIROMICS, subjects with normal $\mathrm{FEV}_{1} / \mathrm{FVC}$, CT-measured residual volume $\left(\mathrm{RV}_{\mathrm{CT}}\right)$ to total lung capacity $\left(\mathrm{TLC}_{\mathrm{CT}}\right.$ ) ratio was measured over $2.5 \pm 0.7$ years of follow-up [59]. Those in the upper $\mathrm{RV}_{\mathrm{CT}} /$ $\mathrm{TLC}_{\mathrm{CT}}$ tertile presented a faster decline in $\mathrm{FEV}_{1} / \mathrm{FVC}$ per year, shorter 6-min walk distance and increased dyspnoea by mMRC compared with those in the lower tertile regardless of demographics, baseline spirometry, respiratory symptom score, smoking status or burden. Therefore, these people were more likely to develop spirometric and symptomatic COPD in upper versus lower $\mathrm{RV}_{\mathrm{CT}} / \mathrm{TLC}_{\mathrm{CT}}$ (OR 5.7, 95\% CI $2.4-$ 13.2; $\mathrm{p}<0.001$ ) [59].

The COPDGene collaborators [18], using environmental exposure, clinical symptoms, CT imaging and spirometric criteria, have proposed a classification of possible, probable and definite COPD diagnoses offering the potential to stimulate both current and future interventions that could slow or halt disease progression in patients before disability or irreversible lung structural changes occur (figure 2) [18].

\section{Forced oscillation technique}

Forced oscillation technique-based phenotyping reflects pathophysiological heterogeneity from a new perspective and correlates with CT assessments [60]. Reference values and minimally important differences for impulse oscillometry in patients with COPD are required for use in clinical interventional trials and become an adjunctive tool to CT imaging in patients with early COPD [61].

For these approaches, we believe that to achieve appropriate and early diagnosis of COPD, a multidimensional diagnostic strategy using exposure history, symptoms, digitalised spirometry, plethysmography with $D_{\mathrm{LCO}}$ and chest CT with increasingly complex analytic tools can broaden our knowledge about early COPD in high-risk populations (figure 1).

\section{Treatment of early COPD}

Evidence on the effectiveness of pharmacological treatment in early or mild COPD is scarce. A recent systematic review [4] showed weak evidence of pharmacological treatments in mild COPD in terms of reduction of hospitalisation, due to lack of evidence of prospective data in mild patients. Post hoc studies from large cohorts such as TORCH (Towards a Revolution in COPD Health) [67] and UPLIFT (Understanding Potential Long-term Impacts on Function with Tiotropium) [68] evaluated pharmacotherapy in patients with moderate COPD and in younger COPD patients. However, the results should be reviewed with caution because the populations did not meet current criteria for mild or early COPD.

One recent study, showed an amelioration of $\mathrm{FEV}_{1}$ decline in mild COPD (COPD Assessment Test $<10$ points, $\mathrm{FEV}_{1}$ GOLD stage I-II) using tiotropium versus placebo $(47 \mathrm{~mL}$ versus $28 \mathrm{~mL}, 95 \%$ CI 2-37; $\mathrm{p}=0.03$ ) [69]. 
We await the results of three ongoing studies, the British Lung Foundation Early COPD Development study (https://clinicaltrials.gov/ identifier NCT03480347), RETHINC trial (REdefining THerapy In Early COPD; https://clinicaltrials.gov/ identifier NCT02867761) and EARLY COPD [70], which are examining whether current and former smokers with respiratory symptoms and meeting the definition of early COPD derive benefit from inhaled bronchodilator therapy.

Nonpharmacological treatments (tobacco cessation, biomass exposure reduction, pulmonary rehabilitation and increased physical activity) are crucial in preventing the progression of COPD. We must regularly

\section{People with risk factors for COPD}

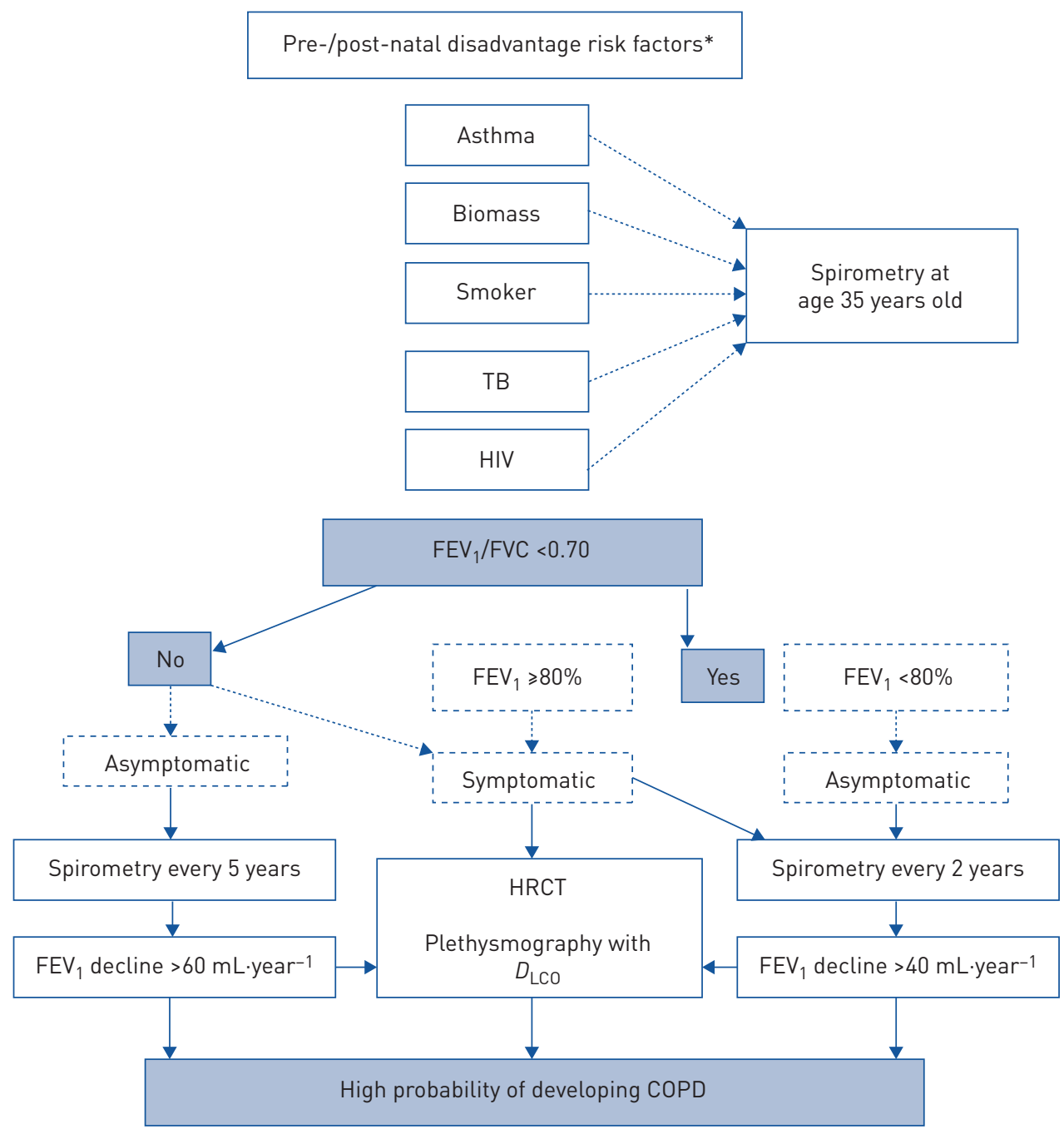

FIGURE 1 Protocol for detecting early pathological changes related to COPD according to risk factors and comorbidities. This protocol take into account the risk factors for early COPD, and proposes an interval for close follow-up [22, 23, 25, 26, 62-65]. If, by age 35 years, spirometry does not present an obstruction (forced expiratory volume in $1 \mathrm{~s}(\mathrm{FEV} 1) /$ forced vital capacity $(\mathrm{FVC})<0.70)$ and the patient is truly asymptomatic, spirometry every 5 years is recommended to detect individuals with rapid FEV1 decline that would fit the definition for early COPD [3]. If the patient is symptomatic, further testing with high-resolution computed tomography (HRCT) and/or plethysmography with diffusing capacity of the lung for carbon monoxide $\left(D_{\mathrm{Lco}}\right)$ or impulse oscillometry (IOS) is recommended to detect early airway trapping, emphysema or diffusion abnormalities prior to spirometric changes. Patients with FEV1/FVC $<0.70$ at age $\geqslant 25$ years and FEV $1>80 \%$ pred but asymptomatic, should be followed with spirometry every 2 years to detect patients who decline fast. Patients with FEV1/FVC $<0.70$, FEV1 $\geqslant 80 \%$ pred and symptomatic should be tested further with HRCT and/or plethysmography with $D_{\mathrm{LCO}}$ or IOS to detect early airway trapping, emphysema or diffusion abnormalities and spirometry every 2 years to detect those patients who decline fast in order to initiate early treatment strategies $[11,18,66]$. TB: tuberculosis. *: prematurity/low birth rate, early life infections, maternal smoking, family respiratory history. 


\begin{tabular}{|c|c|c|c|c|}
\hline & Category & $\begin{array}{l}\text { Odds of change }>350 \mathrm{~mL} \text { in } \mathrm{FEV}_{1} \\
\qquad(95 \% \mathrm{CI})^{\#}\end{array}$ & $\begin{array}{l}\text { All-cause mortality HR } \\
\qquad(95 \% \mathrm{CI})^{1}\end{array}$ & COPDGene 2019 classification \\
\hline$\otimes$ & A & 1.0 (ref) & 1.0 (ref) & No COPD \\
\hline$\otimes$ & B & $1.31(1.04-1.65)$ & $1.05(0.76-1.44)$ & Possible COPD \\
\hline$\otimes$ & C & $1.42(1.07-1.88)$ & $1.55(1.09-2.19)$ & \\
\hline 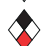 & D & $0.92(0.64-1.30)$ & $1.48(1.03-2.12)$ & \\
\hline$\otimes$ & E & $1.74(1.28-2.36)$ & $1.90(1.33-2.71)$ & Probable COPD \\
\hline$\phi$ & $\mathrm{F}$ & $1.02(0.66-1.60)$ & $2.62(1.84-3.72)$ & \\
\hline 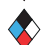 & G & $2.11(1.66-2.68)$ & $1.76(1.36-2.27)$ & \\
\hline$\Delta$ & $\mathrm{H}$ & $2.82(2.18-3.66)$ & $5.18(4.15-6.48)$ & Definite COPD \\
\hline
\end{tabular}

FIGURE 2 Logistic and Cox regression models for forced expiratory volume in $1 \mathrm{~s}\left(\mathrm{FEV}_{1}\right)$ progression and allcause mortality with the proposed COPDGene 2019 classification of categories. Bold indicated categories where $95 \% \mathrm{Cl}$ did not include 1. Black diamond: exposure; blue diamond: abnormal computed tomography imaging; red diamond: abnormal spirometry; purple diamond: symptoms. ${ }^{*}$ : change in $\mathrm{FEV}_{1}$ assessment done on 4925 participants who returned for phase 2 clinical follow-up; adjusted for age at first visit, sex, race, pack-years, current smoking status and baseline $\mathrm{FEV}_{1}$. " ${ }^{\text {?: }}$ mortality assessment done on 8784 participants in the phase 1 cohort; data are implicitly adjusted for age, additionally adjusted for sex, race, pack-years and current smoking. Reproduced from [18] with permission from the publisher.

implement these strategies in primary and secondary care for patients at risk of developing COPD and at patients at the early stages of COPD [5].

\section{Limitations}

This article has several limitations. We reviewed data from smoking-induced COPD because there is a lack of information on early diagnosis in nonsmoking patients with COPD. However, in regions such as Latin America, more than one-third of patients with COPD were never-smokers, which determines that a significant proportion of patients adopt strategies based on similarities with cigarette smoke-induced COPD (symptoms, obstructions, exacerbations), rather than on scientific evidence [71].

Though several studies have linked certain recurring risk factors and comorbidities (childhood asthma, bronchitis, pneumonia, allergic rhinitis, eczema, parental asthma, maternal smoking, female sex, tuberculosis and HIV) with the population who develop airway obstruction [22, 62-65, 72], we lack suitable scores that allow their inclusion as criteria for early COPD.

In addition, asthma-COPD overlap was not evaluated, since its definition criteria and clinical outcomes are heterogeneous and depend on the population studied [73]. Asthma is known to be a risk factor for early-onset COPD [21]; however, currently, there are no specific protocols for the early detection of COPD in patients with a history of asthma that are different from those addressed in this review.

As we wait for updated and validated models and questionnaires that identify at-risk patients before they develop COPD, we have used the available data described in this review to merge global lung development in children with adult respiratory epidemiology to understand the determinants of early COPD and to propose an algorithm that needs testing but has the potential to guide the detection and treatment of early COPD in this population (figure 1).

\section{Conclusions}

After reviewing the evidence, the response to the initial question of whether early diagnosis of COPD is a myth or a true perspective is not straightforward. If we are to modify COPD outcomes, early detection must play a key role. It is therefore vital to define early COPD criteria using prospective multidimensional strategies and to determine an acceptable time-frame from the beginning of symptoms to the diagnosis of COPD. The new evidence coming out is getting us closer to this goal. However, we need to identify and overcome the barriers to diagnosis, have a better understanding of the natural course of the disease and find biomarkers of disease activity to allow better identification of patients who will benefit from earlier interventions to, therefore, have a positive impact on the prognoses of our patients with COPD. 
Conflict of interest: M.E. Laucho-Contreras reports personal fees from GlaxoSmithKline, outside the submitted work. She is also an employee of GlaxoSmithKline Colombia. M. Cohen-Todd has received consulting fees, lecture fees and travel support from AstraZeneca, Boehringer Ingelheim, GlaxoSmithKline, Novartis and Sanofi, outside the submitted work.

\section{References}

1 Lamprecht B, Soriano JB, Studnicka M, et al. Determinants of underdiagnosis of COPD in national and international surveys. Chest 2015; 148: 971-985.

2 Casas Herrera C, Montes de Oca M, López Varela ML, et al. COPD underdiagnosis and misdiagnosis in a high-risk primary care population in four Latin American countries. A key to enhance disease diagnosis: the PUMA study. PLoS One 2016; 11: e0152266.

3 Martinez FJ, Han MK, Allinson JP, et al. At the root: defining and halting progression of early chronic obstructive pulmonary disease. Am J Respir Crit Care Med 2018; 197: 1540-1551.

4 Montes de Oca M, Lopez Varela MV, Acuna A, et al. Incorporating new evidence on inhaled medications in COPD. The Latin American Chest Association (ALAT) 2019. Arch Bronconeumol 2020; 56: 106-113.

5 Global Initiative for Chronic Obstructive Lung Disease (GOLD). Global Strategy for the Diagnosis, Management, and Prevention of Chronic Obstructive Pulmonary Disease, 2020 Report. Available from: www.goldcopd.org2020

6 Montes de Oca M, Lopez Varela MV, Laucho-Contreras ME, et al. Classification of patients with chronic obstructive pulmonary disease according to the Latin American Thoracic Association (ALAT) staging systems and the global initiative for chronic obstructive pulmonary disease (GOLD). Arch Bronconeumol 2017; 53: 98-106.

7 Casanova C, de Torres JP, Aguirre-Jaime A, et al. The progression of chronic obstructive pulmonary disease is heterogeneous: the experience of the BODE cohort. Am J Respir Crit Care Med 2011; 184: 1015-1021.

8 Vestbo J, Edwards LD, Scanlon PD, et al. Changes in forced expiratory volume in 1 second over time in COPD. $N$ Engl J Med 2011; 365: 1184-1192.

9 Halpin DMG, de Jong HJI, Carter V, et al. Distribution, temporal stability and appropriateness of therapy of patients with COPD in the UK in relation to GOLD 2019. EClinicalMedicine 2019; 14: 32-41.

10 Stringer WW, Porszasz J, Bhatt SP, et al. Physiologic insights from the COPD genetic epidemiology study. Chronic Obstr Pulm Dis 2019; 6: 256-266.

11 Lange $\mathrm{P}$, Celli B, Agusti A, et al. Lung-function trajectories leading to chronic obstructive pulmonary disease. $N$ Engl J Med 2015; 373: 111-122.

12 Agusti A, Celli B. Avoiding confusion in COPD: from risk factors to phenotypes to measures of disease characterisation. Eur Respir J 2011; 38: 749-751.

13 Di Marco F, Balbo P, de Blasio F, et al. Early management of COPD: where are we now and where do we go from here? A Delphi consensus project. Int J Chron Obstruct Pulmon Dis 2019; 14: 353-360.

14 Jones RC, Price D, Ryan D, et al. Opportunities to diagnose chronic obstructive pulmonary disease in routine care in the UK: a retrospective study of a clinical cohort. Lancet Respir Med 2014; 2: 267-276.

15 Larsson K, Janson C, Stallberg B, et al. Impact of COPD diagnosis timing on clinical and economic outcomes: the ARCTIC observational cohort study. Int J Chron Obstruct Pulmon Dis 2019; 14: 995-1008.

16 Pauwels RA, Buist AS, Calverley PM, et al. Global strategy for the diagnosis, management, and prevention of chronic obstructive pulmonary disease. NHLBI/WHO Global Initiative for Chronic Obstructive Lung Disease (GOLD) Workshop summary. Am J Respir Crit Care Med 2001; 163: 1256-1276.

17 Lambert AA, Bhatt SP. Respiratory symptoms in smokers with normal spirometry: clinical significance and management considerations. Curr Opin Pulm Med 2019; 25: 138-143.

18 Lowe KE, Regan EA, Anzueto A, et al. COPDGene((R)) 2019: redefining the diagnosis of chronic obstructive pulmonary disease. Chronic Obstr Pulm Dis 2019; 6: 384-399.

19 Vestbo J, Lange P. Can GOLD Stage 0 provide information of prognostic value in chronic obstructive pulmonary disease? Am J Respir Crit Care Med 2002; 166: 329-332.

20 Perez-Padilla R, Wehrmeister FC, de Oca MM, et al. Outcomes for symptomatic non-obstructed individuals and individuals with mild (GOLD stage 1) COPD in a population based cohort. Int J Chron Obstruct Pulmon Dis 2018; 13: 3549-3561

21 McGeachie MJ. Childhood asthma is a risk factor for the development of chronic obstructive pulmonary disease. Curr Opin Allergy Clin Immunol 2017; 17: 104-109.

22 Bui DS, Lodge CJ, Burgess JA, et al. Childhood predictors of lung function trajectories and future COPD risk: a prospective cohort study from the first to the sixth decade of life. Lancet Respir Med 2018; 6: 535-544.

23 Allinson JP, Hardy R, Donaldson GC, et al. Combined impact of smoking and early-life exposures on adult lung function trajectories. Am J Respir Crit Care Med 2017; 196: 1021-1030.

24 Guerra S, Stern DA, Zhou M, et al. Combined effects of parental and active smoking on early lung function deficits: a prospective study from birth to age 26 years. Thorax 2013; 68: 1021-1028.

25 Belgrave DCM, Granell R, Turner SW, et al. Lung function trajectories from pre-school age to adulthood and their associations with early life factors: a retrospective analysis of three population-based birth cohort studies. Lancet Respir Med 2018; 6: 526-534.

26 McGeachie MJ, Yates KP, Zhou X, et al. Patterns of growth and decline in lung function in persistent childhood asthma. N Engl J Med 2016; 374: 1842-1852.

27 Duarte-de-Araujo A, Fonte P, Teixeira P, et al. Is an early diagnosis of COPD clinically useful? Arch Bronconeumol 2020; 56: 409-410.

28 Colak Y, Afzal S, Nordestgaard BG, et al. Prognosis of asymptomatic and symptomatic, undiagnosed COPD in the general population in Denmark: a prospective cohort study. Lancet Respir Med 2017; 5: 426-434.

29 Miravitlles M, Soriano JB, Garcia-Rio F, et al. Prevalence of COPD in Spain: impact of undiagnosed COPD on quality of life and daily life activities. Thorax 2009; 64: 863-868.

30 Labonte LE, Tan WC, Li PZ, et al. Undiagnosed chronic obstructive pulmonary disease contributes to the burden of health care use. Data from the CanCOLD Study. Am J Respir Crit Care Med 2016; 194: 285-298.

31 Colak Y, Afzal S, Nordestgaard BG, et al. Prevalence, characteristics, and prognosis of early chronic obstructive pulmonary disease. The Copenhagen General Population Study. Am J Respir Crit Care Med 2020; 201: 671-680. 
32 Guirguis-Blake JM, Senger CA, Webber EM, et al. Screening for chronic obstructive pulmonary disease: evidence report and systematic review for the US Preventive Services Task Force. JAMA 2016; 315: 1378-1393.

33 Scioscia G, Blanco I, Arismendi E, et al. Different dyspnoea perception in COPD patients with frequent and infrequent exacerbations. Thorax 2017; 72: 117-121.

34 Yawn BP, Wollan PC. Knowledge and attitudes of family physicians coming to COPD continuing medical education. Int J Chron Obstruct Pulmon Dis 2008; 3: 311-317.

35 Price DB, Tinkelman DG, Halbert RJ, et al. Symptom-based questionnaire for identifying COPD in smokers. Respiration 2006; 73: 285-295.

36 Hanania NA, Mannino DM, Yawn BP, et al. Predicting risk of airflow obstruction in primary care: validation of the lung function questionnaire (LFQ). Respir Med 2010; 104: 1160-1170.

37 Martinez FJ, Raczek AE, Seifer FD, et al. Development and initial validation of a self-scored COPD Population Screener Questionnaire (COPD-PS). COPD 2008; 5: 85-95.

38 Varela MV L, de Oca M M, Wehrmeister FC, et al. External validation of the PUMA COPD diagnostic questionnaire in a general practice sample and the PLATINO study population. Int J Chron Obstruct Pulmon Dis 2019; 14: 1901-1911.

39 Leidy NK, Martinez FJ, Malley KG, et al. Can CAPTURE be used to identify undiagnosed patients with mild-to-moderate COPD likely to benefit from treatment? Int J Chron Obstruct Pulmon Dis 2018; 13: 1901-1912.

40 Enright PL, Beck KC, Sherrill DL. Repeatability of spirometry in 18,000 adult patients. Am J Respir Crit Care Med 2004; 169: 235-238.

41 De Ramon Fernandez A, Ruiz Fernandez D, Marcos-Jorquera D, et al. Support system for early diagnosis of chronic obstructive pulmonary disease based on the service-oriented architecture paradigm and business process management strategy: development and usability survey among patients and health care providers. J Med Internet Res 2020; 22: e17161.

42 Hoesterey D, Das N, Janssens W, et al. Spirometric indices of early airflow impairment in individuals at risk of developing COPD: spirometry beyond FEV1/FVC. Respir Med 2019; 156: 58-68.

43 Chhabra SK. Forced vital capacity, slow vital capacity, or inspiratory vital capacity: which is the best measure of vital capacity? J Asthma 1998; 35: 361-365.

44 Marsh S, Aldington S, Williams M, et al. Complete reference ranges for pulmonary function tests from a single New Zealand population. N Z Med J 2006; 119: U2281.

45 Saint-Pierre M, Ladha J, Berton DC, et al. Is the slow vital capacity clinically useful to uncover airflow limitation in subjects with preserved FEV1/FVC ratio? Chest 2019; 156: 497-506.

46 Hansen JE, Porszasz J, Casaburi R, et al. Re-defining lower limit of normal for FEV1/FEV6, FEV1/FVC, FEV3/ FEV6 and FEV3/FVC to improve detection of airway obstruction. Chronic Obstr Pulm Dis 2015; 2: 94-102.

47 Prats E, Tejero E, Pardo P, et al. Prognostic value of the six-second spirometry in patients with chronic obstructive pulmonary disease: a cohort study. PLoS One 2015; 10: e0140855.

48 Jing JY, Huang TC, Cui W, et al. Should FEV1/FEV6 replace FEV1/FVC ratio to detect airway obstruction? A meta analysis. Chest 2009; 135: 991-998.

49 Bhatt SP, Kim YI, Wells JM, et al. FEV(1)/FEV(6) to diagnose airflow obstruction. Comparisons with computed tomography and morbidity indices. Ann Am Thorac Soc 2014; 11: 335-341.

50 Morris ZQ, Huda N, Burke RR. The diagnostic importance of a reduced FEV1/FEV6. COPD 2012; 9: 22-28.

51 Lee SM, Seo JB, Lee SM, et al. Optimal threshold of subtraction method for quantification of air-trapping on coregistered CT in COPD patients. Eur Radiol 2016; 26: 2184-2192.

52 Kornmann O, Beeh KM, Beier J, et al. Newly diagnosed chronic obstructive pulmonary disease. Clinical features and distribution of the novel stages of the Global Initiative for Obstructive Lung Disease. Respiration 2003; 70: 67-75.

53 Bird Y, Staines-Orozco H. Pulmonary effects of active smoking and secondhand smoke exposure among adolescent students in Juarez, Mexico. Int J Chron Obstruct Pulmon Dis 2016; 11: 1459-1467.

54 Zeng S, Tham A, Bos B, et al. Lung volume indices predict morbidity in smokers with preserved spirometry. Thorax 2019; 74: 114-124.

55 Harvey BG, Strulovici-Barel Y, Kaner RJ, et al. Risk of COPD with obstruction in active smokers with norma spirometry and reduced diffusion capacity. Eur Respir J 2015; 46: 1589-1597.

56 McDonough JE, Yuan R, Suzuki M, et al. Small-airway obstruction and emphysema in chronic obstructive pulmonary disease. N Engl J Med 2011; 365: 1567-1575.

57 Mohamed Hoesein FA, de Jong PA, Lammers JW, et al. Airway wall thickness associated with forced expiratory volume in 1 second decline and development of airflow limitation. Eur Respir J 2015; 45: 644-651.

58 Koo HK, Vasilescu DM, Booth S, et al. Small airways disease in mild and moderate chronic obstructive pulmonary disease: a cross-sectional study. Lancet Respir Med 2018; 6: 591-602.

59 Arjomandi M, Zeng S, Barjaktarevic I, et al. Radiographic lung volumes predict progression to COPD in smokers with preserved spirometry in SPIROMICS. Eur Respir J 2019; 54: 1802214

60 Matsuo Y, Ogawa E, Seto-Yukimura R, et al. Novel respiratory impedance-based phenotypes reflect different pathophysiologies in chronic obstructive pulmonary disease patients. Int J Chron Obstruct Pulmon Dis 2019; 14: 2971-2977.

61 Lipworth BJ, Jabbal S. What can we learn about COPD from impulse oscillometry? Respir Med 2018; 139: 106-109.

62 Byrne AL, Marais BJ, Mitnick CD, et al. Tuberculosis and chronic respiratory disease: a systematic review. Int $J$ Infect Dis 2015; 32: 138-146.

63 Yakar HI, Gunen H, Pehlivan E, et al. The role of tuberculosis in COPD. Int J Chron Obstruct Pulmon Dis 2017; 12: 323-329.

64 Bigna JJ, Kenne AM, Asangbeh SL, et al. Prevalence of chronic obstructive pulmonary disease in the global population with HIV: a systematic review and meta-analysis. Lancet Glob Health 2018; 6: e193-e202.

65 Gingo MR, Nouraie M, Kessinger CJ, et al. Decreased lung function and all-cause mortality in HIV-infected individuals. Ann Am Thorac Soc 2018; 15: 192-199.

66 Petersen H, Sood A, Polverino F, et al.. The course of lung function in middle-aged heavy smokers: incidence and time to early onset of chronic obstructive pulmonary disease. Am J Respir Crit Care Med 2018; 198: 1449-1451. 
67 Jenkins CR, Jones PW, Calverley PM, et al. Efficacy of salmeterol/fluticasone propionate by GOLD stage of chronic obstructive pulmonary disease: analysis from the randomised, placebo-controlled TORCH study. Respir Res 2009; 10: 59.

68 Decramer M, Celli B, Kesten S, et al. Effect of tiotropium on outcomes in patients with moderate chronic obstructive pulmonary disease (UPLIFT): a prespecified subgroup analysis of a randomised controlled trial. Lancet 2009; 374: 1171-1178.

69 Zhou Y, Zhong NS, Li X, et al. Tiotropium in early-stage chronic obstructive pulmonary disease. N Engl J Med 2017; 377: 923-935.

70 Borras-Santos A, Garcia-Aymerich J, Soler-Cataluna JJ, et al. Determinants of the appearance and progression of early-onset chronic obstructive pulmonary disease in young adults. A case-control study with follow-up. Arch Bronconeumol 2019; 55: 312-318.

71 Perez-Padilla R, Menezes AMB. Chronic obstructive pulmonary disease in Latin America. Ann Glob Health 2019; 85: 7.

72 Foreman MG, Zhang L, Murphy J, et al. Early-onset chronic obstructive pulmonary disease is associated with female sex, maternal factors, and African American race in the COPDGene Study. Am J Respir Crit Care Med 2011; 184: 414-420.

73 Laucho-Contreras M, de Oca MM, Owen CA. Asthma COPD overlap syndrome: an approach to a real-world endotype in obstructive lung disease? Curr Pharm Des 2016; 22: 6273-6282. 